\title{
Aerogels as Promising Thermal Insulating Materials: An Overview
}

\author{
Prakash C. Thapliyal and Kirti Singh \\ Organic Building Materials Group, CSIR-Central Building Research Institute, Roorkee 247667, India \\ Correspondence should be addressed to Kirti Singh; kirti4444@rediffmail.com
}

Received 11 January 2014; Accepted 11 February 2014; Published 27 April 2014

Academic Editor: Iwan Kityk

Copyright (C) 2014 P. C. Thapliyal and K. Singh. This is an open access article distributed under the Creative Commons Attribution License, which permits unrestricted use, distribution, and reproduction in any medium, provided the original work is properly cited.

\begin{abstract}
Aerogels are solids with high porosity $(<100 \mathrm{~nm})$ and hence possess extremely low density $\left(\sim 0.003 \mathrm{~g} / \mathrm{cm}^{3}\right)$ and very low conductivity $(\sim 10 \mathrm{~mW} / \mathrm{mK})$. In recent years, aerogels have attracted more and more attention due to their surprising properties and their existing and potential applications in wide range of technological areas. An overview of aerogels and their applications as the building envelope components and respective improvements from an energy efficiency perspective including performance is given here. This overview covers thermal insulation properties of aerogels and studies regarding structural features which will be helpful in buildings envelope. The improvements of thermal insulation systems have future prospects of large savings in primary energy consumption. It can be concluded that aerogels have great potential in a wide range of applications as energy efficient insulation, windows, acoustics, and so forth.
\end{abstract}

\section{Introduction}

Short supply, limited availability, and increasing energy costs all around the world emphasize the need for immediate energy conservation in both oil rich and oil producing countries. An effective way towards saving energy is to improve the thermal insulation of buildings especially in hot climates where the energy demand for cooling by air conditioning is comparatively higher. In addition to the need for energy saving, high insulating materials are further justified by improved comfort levels and increased building life. Thermal characteristics depend largely on the thermal conductivity of the cell walls and the cell matrix, as well as radiation and convection, with the cell matrix being the most significant factor in determining the overall heat transfer characteristics. Thermal properties of some commonly available insulating materials are given in Table 1.

Thermal conductivity varies with time due to changes in the composition of the cell matrix. The ambient air and external building surface temperatures in hot climates of Asia and Africa are much higher than in cold climates of a Australia, Europe and America, temperature of $38^{\circ} \mathrm{C}$ should be taken into account while calculating thermal conductivities at ageing. In addition to the product specific parameter of the change of the thermal conductivity, mean temperature and water absorption are also other important influencing factors.

As per IUPAC, aerogel is defined as a gel comprised of a microporous solid in which dispersed phase is a gas [1]. Aegerter et al. defined aerogels as gels in which the liquid has been replaced with air, with very moderate shrinkage of a solid network [2]. Aerogel is basically a synthetic porous ultralight material derived from a gel, in which the liquid component of the gel has been replaced with a gas; for example, graphene aerogels are so light that they can rest on top of a grass leaf. The combination of high porosity and extremely small pores provides aerogels with their extreme properties: solid with extremely low density and low thermal conductivity [3]. Aerogels are sometimes also known by different names such as frozen smoke, solid smoke, solid air, or blue smoke owing to translucent nature and the way light scatters in the material [4]. Typical structure of an aerogel is shown in Figure 1.

Aerogels together with vacuum insulation panels are one of the new promising high performance thermal and acoustic insulation materials for possible building applications and 
TABLE 1: Commonly available thermal insulation materials.

\begin{tabular}{llcccl}
\hline S. number & Material & $R$-value (per inch) & Green & Flammable & Remark \\
\hline 1 & Mineral wool & $R-3.1$ & Yes & No & Does not melt or support combustion \\
2 & Fibreglass & $R-3.1$ & Yes & No & Does not absorb water \\
3 & Polystyrene (EPS) & $R-4$ & No & Yes & $\begin{array}{l}\text { Is difficult to use around imperfections; can become } \\
\text { costly }\end{array}$ \\
4 & Polyurethane foam & $R-6.3$ & No & Yes & Makes a great sound insulator \\
5 & Cellulose & $R-3.7$ & Yes & Yes & Contains the highest amount of recycled content \\
\hline
\end{tabular}

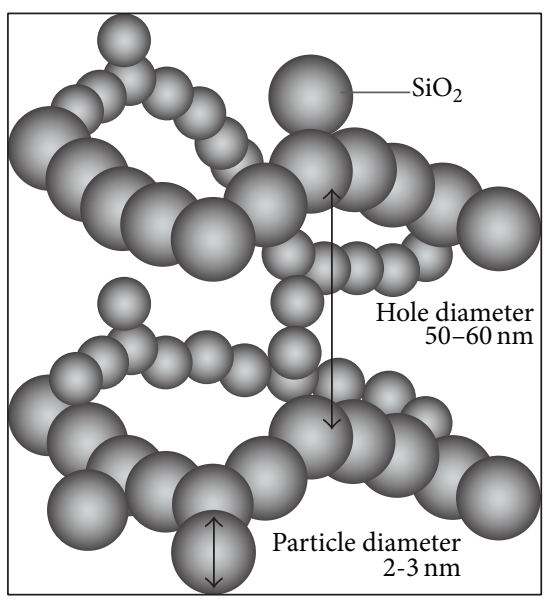

(a)

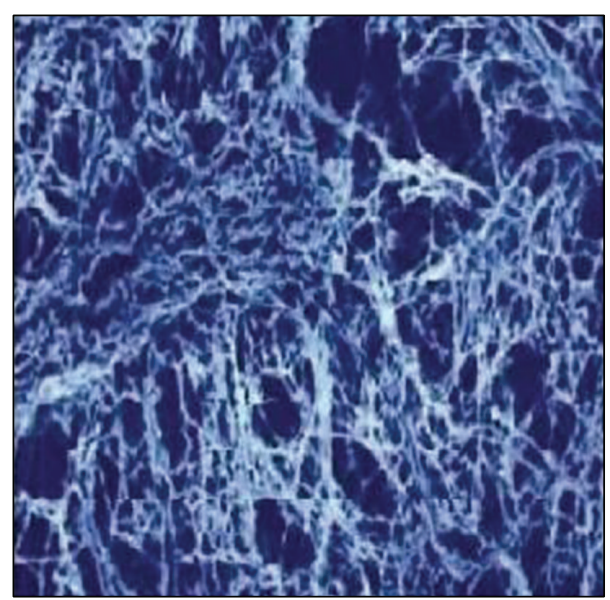

(b)

Figure 1: Nanometer scale particles and pores in an aerogel. (a) Network architecture of an aerogel [77]. (b) Electron micrograph of a silica aerogel [78].

TABLE 2: Commercial aerogel products.

\begin{tabular}{|c|c|c|c|}
\hline S. number & Product & Applications & References \\
\hline 1 & Cabot & $\begin{array}{l}\text { (i) Pellets, composites } \\
\text { (ii) Day lighting applications } \\
\text { (iii) Oil and gas pipeline insulation } \\
\text { (iv) Cryoinsulation }\end{array}$ & {$[73,74]$} \\
\hline 2 & $\begin{array}{c}\text { Aspen } \\
\text { aerogels }\end{array}$ & $\begin{array}{l}\text { (i) Construction materials } \\
\text { (ii) Flexible blanket insulation } \\
\text { (iii) Oil and gas pipeline } \\
\text { (iv) Aerospace, apparel }\end{array}$ & [74-76] \\
\hline 3 & Nanopore & $\begin{array}{l}\text { (i) Vacuum insulation panels } \\
\text { (ii) Shipping containers } \\
\text { (iii) Refrigeration } \\
\text { (iv) Apparel }\end{array}$ & {$[74]$} \\
\hline
\end{tabular}

are currently the main market for aerogels, whereas other applications such as absorbents, shock absorbers, nuclear waste storage, batteries, and catalysts are also possible [5-13]. A list of commercial available aerogels with their trade names is given in Table 2 .
Aerogels are typically characterized by low density solid, low optical index of refraction, low thermal conductivity, low speed of sound through materials, high surface area, and low dielectric constant.

In this paper authors gave an overview of aerogels and their applications as the building envelope components and respective improvements from an energy efficiency perspective. This covers thermal insulation properties of aerogels and studies regarding structural features which will be helpful in buildings envelope. This overview is presented in two parts: firstly, the general discussion of aerogels regarding how they have such a high thermal quality and what are their physical properties which will be useful in making insulating materials and secondly, their remarkable properties due to extraordinary physical and chemical structure of aerogels.

\section{Aerogels}

The passage of thermal energy through an insulating material occurs through three mechanisms: solid conductivity, gaseous conductivity, and radiative (infrared) transmission. The sum of these three components gives the total thermal conductivity of the material. Solid conductivity is an intrinsic property of a specific material. The improvement of thermal 
resistance of the building envelope can be achieved by decreasing the thermal conductivity.

Fricke et al. observed that both the solid conductivity and the gas conductivity were proportional to the density as shown below:

$$
\begin{aligned}
& \lambda_{\text {gas }} \propto \rho^{-0.6} \\
& \lambda_{\text {solid }} \propto \rho^{1.5} .
\end{aligned}
$$

Hümmer et al. using these relations derived the following relation for the radiative conductivity, which is a relative equation for the thermal conductivity of opacified silica aerogels:

$$
\begin{aligned}
\lambda_{\text {total }}(\rho)= & \lambda_{\text {solid }, 0}\left(\frac{\rho}{\rho_{0}}\right)^{1.5}+\lambda_{\text {gas }, 0}\left(\frac{\rho}{\rho_{0}}\right)^{-0.6} \\
& +\lambda_{\text {rad }, 0}\left(\frac{\rho}{\rho_{0}}\right)^{-1}\left(\frac{T}{T_{0}}\right)^{3}
\end{aligned}
$$

where $\rho\left(\mathrm{kg} / \mathrm{m}^{3}\right)$ is the density; $\lambda_{\text {total }}, \lambda_{\text {gas }}, \lambda_{\text {solid }}$, and $\lambda_{\text {rad }}$ $(\mathrm{W} / \mathrm{m} . \mathrm{K})$ are the total conductivity, the conductivity for gas conduction, the conductivity for solid conduction, and the radiative conductivity, respectively; $T\left({ }^{0} \mathrm{~K}\right)$ is the temperature, and the index 0 means that parameters are related to a reference material from an aerogel [14].

Aerogel is made of more than $90 \%$ of air, having extremely low weight, transparency, and excellent thermal conductivity. Aerogel is an ideal material for thermal insulation due to all these properties $[15,16]$. Also their high visible solar transmittance $\left(T_{\text {vis }}\right)$ is desirable for application in windows. Further decrease in thermal conductivity of aerogel can be observed if evacuated below $50 \mathrm{hPa}$; thermal conductivity decreased because of elimination of pore gas. Superinsulations with extremely low thermal conductivities can be implemented with evacuated highly porous powder, fiber, or gel spacers. Due to the Knudsen effect, thermal conductivity can become lower than that for the still air, that is, even less than $25 \mathrm{~mW} / \mathrm{mK}$ [17].

For example, silica aerogel is a highly porous material with pore diameters in the range of $10-100 \mathrm{~nm}$. The porosity is more than $90 \%$ with a thermal conductivity lower than that of air, which makes these aerogels a highly insulating material. The space not occupied by solids in an aerogel is normally filled with air (or another gas) unless the material is sealed under vacuum. These gases can also transport thermal energy through the aerogel. The pores of silica aerogel are open and allow the passage of gas through the material. The final mode of thermal transport through silica aerogels involves infrared radiation [14]. Soleimani Dorcheh and Abbasi reported the synthesis of nanostructured silicon based transparent aerogels with pore diameter 20-40 nm [18].

Water molecules do not interact strongly with the hydrophobic aerogel pore walls and therefore will not lose much energy in colliding with the wall and the progress of these molecules will not be significantly slowed. Accordingly, the aerogel possesses high breathability, that is, high permeation selectivity between water vapor and agent vapors. Titania aerogels demonstrated an excellent mesoporous structure for application as photoanodes of dye-sensitized solar cells with power conversion efficiency improvement of 16\% [19]. Sol-gel derived silica has found tremendous applications as a biocompatible scaffold for the immobilization of cells. A new method for rapid, reproducible, and sensitive detection of rhizobia using aerogels has been reported for the first time [20].

Thermal insulation properties of aerogels are closely related to their acoustic properties too. The acoustic propagation in aerogels depends on the interstitial gas nature and pressure, density, and more generally the texture [21]. Different applications of aerogels are given in Figure 4.

\section{Classification of Aerogels}

Aerogels can be classified on the basis of the following [22].

(a) On the basis of appearance

(i) Monolith

(ii) Powder

(iii) Film/felts

(b) On the basis of preparation methods

(i) Aerogel

(ii) Xerogel

(iii) Cryogel

(iv) Other aerogel-related materials

(c) On the basis of different microstructures

(i) Microporous aerogel $(<2 \mathrm{~nm})$

(ii) Mesoporous aerogel $(2-50 \mathrm{~nm})$

(iii) Mixed porous aerogel

(d) On the basis of chemical structure

(i) Oxides

(ii) Polymers

(iii) Mixed

(iv) Hybrid

(v) Composite.

\section{Preparation -of Aerogels}

Different type of aerogels can be prepared using alumina, chromium, tin oxide, and carbon, but preparation of silica based aerogel is comparatively easier and reliable. Aerogels are synthesized via a sol-gel process consisting of three main steps [Figure 3].

(1) Gel Preparation. Solid nanoparticles grow crosslink and finally form a three-dimensional solid network with solvent filled pores. To begin with a gel is created in solution and then the liquid is carefully removed to leave the aerogel intact; initially the creation of a colloidal suspension of solid particles known as a "sol" takes place; for example, silica gels 
are synthesized by hydrolyzing monomeric tetrafunctional and trifunctional silicon alkoxide precursors employing a mineral acid or a base as a catalyst [23, 24]. There are many ways to create silica based sol gels. One is by mixing tetraethoxysilane $\mathrm{Si}\left(\mathrm{OC}_{2} \mathrm{H}_{5}\right)_{4}$ with ethanol and water to make it polymerize and thus producing a water based silica gel as shown in (3). A solvent, such as methanol, is used to extract and replace the water [25]:

$$
\begin{aligned}
& \mathrm{Si}\left(\mathrm{OCH}_{2} \mathrm{C}_{3}\right)_{4} \text { (liq.) }+2 \mathrm{H}_{2} \text { (liq.) } \\
& \quad \longrightarrow \mathrm{SiO}_{2} \text { (solid) }+\mathrm{CH}_{2} \mathrm{CH}_{3} \mathrm{OH} \text { (liq.) }
\end{aligned}
$$

(2) Aging of the Gel. It provides strength to the structure of gel. The gel prepared earlier is aged in its mother solution [26]. This aging process strengthens the gel, so that minimum shrinkage occurs during the drying step [27]. After gelification, the gel is left undisturbed in the solvent to complete the reaction. After completion of reaction the aerogel product is formed. Inorganic aerogels can be prepared via sol-gel processing, a technique which requires alkoxides or metal salts in alcoholic or aqueous solutions, and subjecting to supercritical drying.

(3) Drying. The solvent has to be removed whilst preserving the solid aerogel network. This can be done either by supercritical drying or at ambient conditions. Aerogel materials are typically prepared by removing the solvent contained in a gel matrix by extraction in a supercritical fluid medium. This can be accomplished by bringing the gel solvent system above its critical temperature and pressure and subsequently relieving pressure above the critical temperature until only vapor remains.

Alternatively, the gel solvent system can be extracted from the wet gel with an appropriate solvent. Liquid carbon dioxide is the most popular extraction solvent because it is inexpensive and has a relatively low critical temperature and critical pressure [28-31].
Crack-free silica aerogels can also be obtained via solvent exchange and resulting surface modification of wet gels using either isopropyl alcohol, trimethylchlorosilane, or n-hexane solution [32]. The physics and chemistry involved in the synthesis of aerogels are detailed in the literature on aerogels [18, 23, 33-37].

For dense silica, solid conductivity is relatively high (a single pane window transmits a large amount of thermal energy). However, silica aerogels possess a very small ( 1$10 \%)$ fraction of solid silica. Additionally, the solids that are present consist of very small particles linked in a threedimensional network with many "dead-ends." Therefore, thermal transport through the solid portion of silica aerogel occurs through a very tortuous path and is not particularly effective [38]. Use of methyltrimethoxysilane coprecursor makes the aerogel hydrophobic and makes it able to hold water droplets on the surface [39]. Porosity of silica aerogels was determined by helium pycnometry using the following formula and was found to be $1900 \mathrm{~kg} / \mathrm{m}^{3}$ [40]:

$$
\operatorname{Porosity}(\%)=\left(1-\frac{\rho_{b}}{\rho_{s}}\right) \text {, }
$$

where $\rho_{b}$ is the bulk density and $\rho_{s}$ is the skeleton density.

The hydrophobic aerogels have also been obtained via coprecursor method pioneered by Schmidt and Schwertfeger [13]. Hydrolysis and condensation rates of all the coprecursors were observed to be slower than that of TEOS because the former contains one or more nonreactive alkyl/aryl groups, which are nonhydrolysable, and a three-dimensional solid network is achieved as per the following chemical reaction:

$$
\mathrm{nSi}\left(\mathrm{OC}_{2} \mathrm{H}_{5}\right)_{4}+2 \mathrm{H}_{2} \mathrm{O} \underset{\text { Oxalic Acid }}{\stackrel{\mathrm{C}_{2} \mathrm{H}_{5} \mathrm{OH}}{\longrightarrow}} \mathrm{SiO}_{2}+4 \mathrm{n} \mathrm{C}_{2} \mathrm{H}_{5} \mathrm{OH}
$$

When sufficient amount of TEOS has hydrolyzed, the silyl groups of the coprecursor get attached to the silica clusters as per the following chemical reactions:
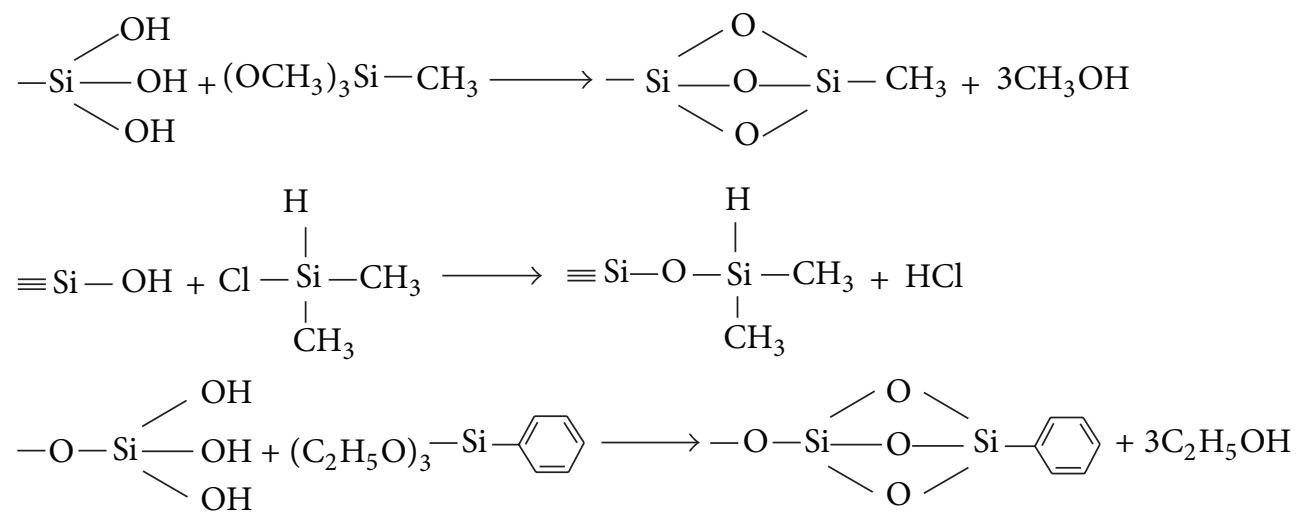

As the silica clusters get attached to nonhydrolysable organic groups (silyl) on their surfaces, the aerogels become hydrophobic. Hydrophobicity of aerogels will increase with the numbers of alkyl/aryl groups attached to the surface [41]. 


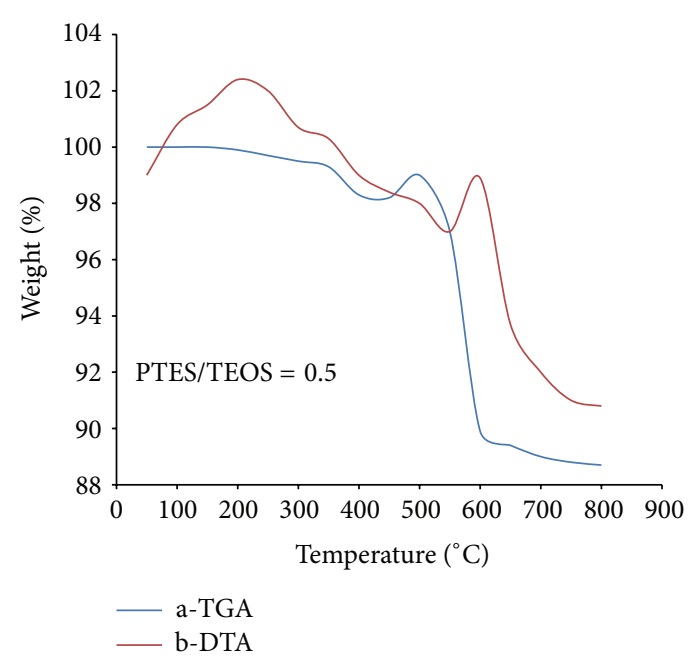

(a)

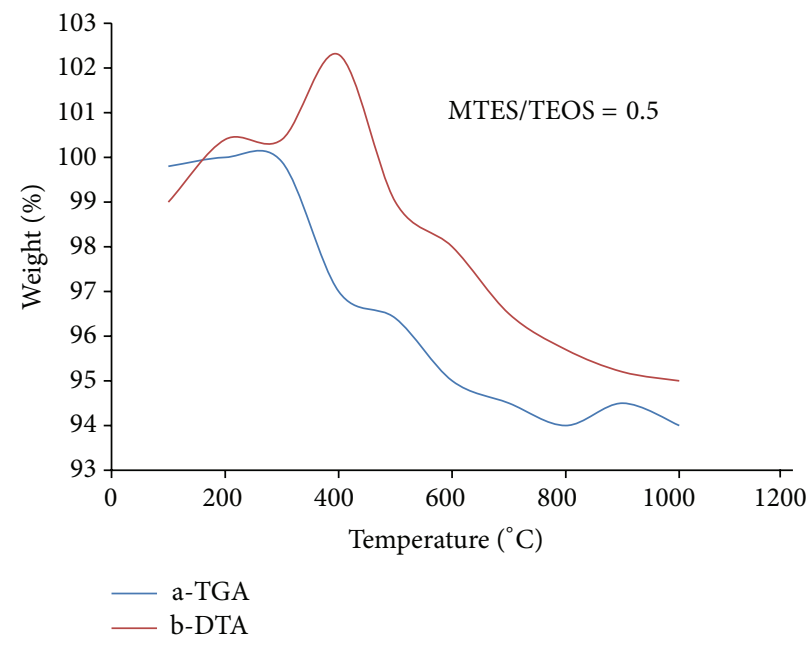

(b)

Figure 2: TGA and DTA analyses of the hydrophobic silica aerogels. (a) PTES/TEOS $=0.5$. (b) MTES/TEOS $=0.5$ [79].
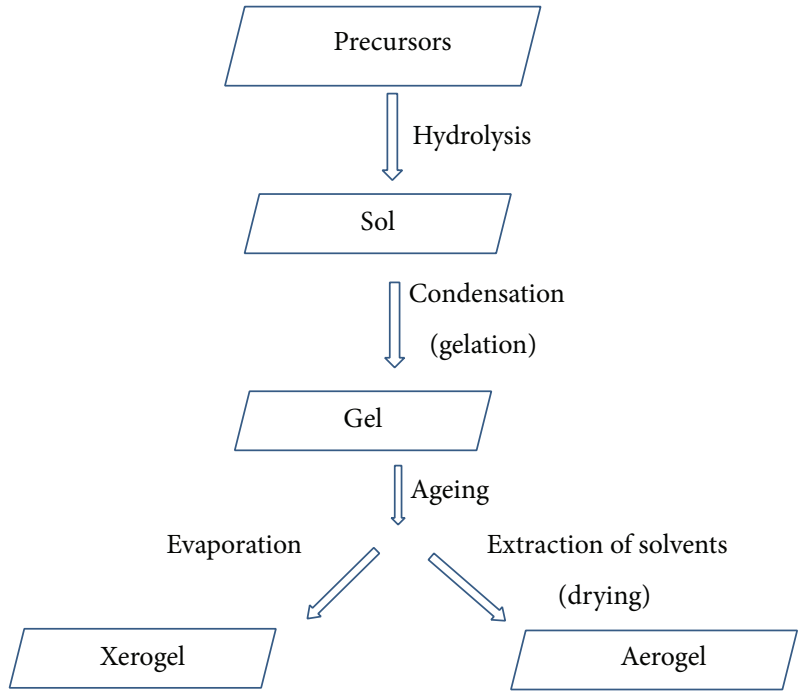

FIGURE 3: Distinct step of aerogel production [80].

In case of organic aerogels derived from the sol-gel polymerization of resorcinol with formaldehyde, thermal conductivity components are clearly correlated with the aerogel structure; that is, the solid conductivity can be determined by the porosity and connectivity between the particles while the gaseous conductivity can be influenced by pore size and mass specific infrared absorption of the building units influences radiative transport [42].

Polymer aerogels were prepared from mixtures containing a fixed stoichiometric amount of formaldehyde and varying proportions of resorcinol (RF) and 2,4-dihydroxybenzoic acid (DHBAF) with the objective of combining the advantages of high mesopore volume and solids content of RF aerogels with the ion exchange capacity of DHBAF aerogels, and results show that the aerogel properties vary systematically as the synthesis conditions are changed. It was found that the addition of $\mathrm{R}$ to the synthesis mixture resulted in increased values of surface area, mesopore volume, and mean diameter, while simultaneously maintaining the ion exchange capacity of the wet gel $[43,44]$.

In the TG-DTA of some of the silica aerogel samples there is rapid increase in the weight loss of hydrophilic silica aerogels at $50-100^{\circ} \mathrm{C}$ due to evaporation of trapped $\mathrm{H}_{2} \mathrm{O}$ and alcoholic groups from hydrophilic silica aerogels which were produced by the condensation reactions of $\mathrm{Si}-\mathrm{OH}$ and $\mathrm{Si}\left(\mathrm{OC}_{2} \mathrm{H}_{5}\right)$ groups, whereas the percentage of weight loss is negligible up to the temperature of thermal stability in case of hydrophobic aerogels [42].

The effect of heat treatment on the hydrophobicity and specific surface area has been also investigated by several researchers. The results of these studies indicate that hydrophobicity of silica aerogel decreased with increasing the heating temperature to $350^{\circ} \mathrm{C}$. On further increasing the heating temperature to $500^{\circ} \mathrm{C}$, silica aerogel becomes completely hydrophilic (Figure 2). Some results for MTES coprecursor based aerogels show that the hydrophobicity of the silica around $573 \mathrm{~K}$ corresponding to oxidation of aerogel could be maintained up to $350^{\circ} \mathrm{C}[45,46]$.

\section{Structural Features}

Aerogels have an unusual combination of high porosity and small pore size, making porosity characterization by conventional techniques, such as mercury intrusion, thermoporometry, and nitrogen adsorption/desorption, very difficult. All these techniques are based on the application of capillary pressures on the aerogel network, which may cause large volumetric compressions, leading to incorrect values for pore size and volume [27]. Aerogels are characterized with a very low permeability which can be explained in terms of pore size suitable for transport of water vapours/gases but not for water molecules [46]. Some aerogels such as carbon aerogels can be obtained in the form of monoliths, beads, 


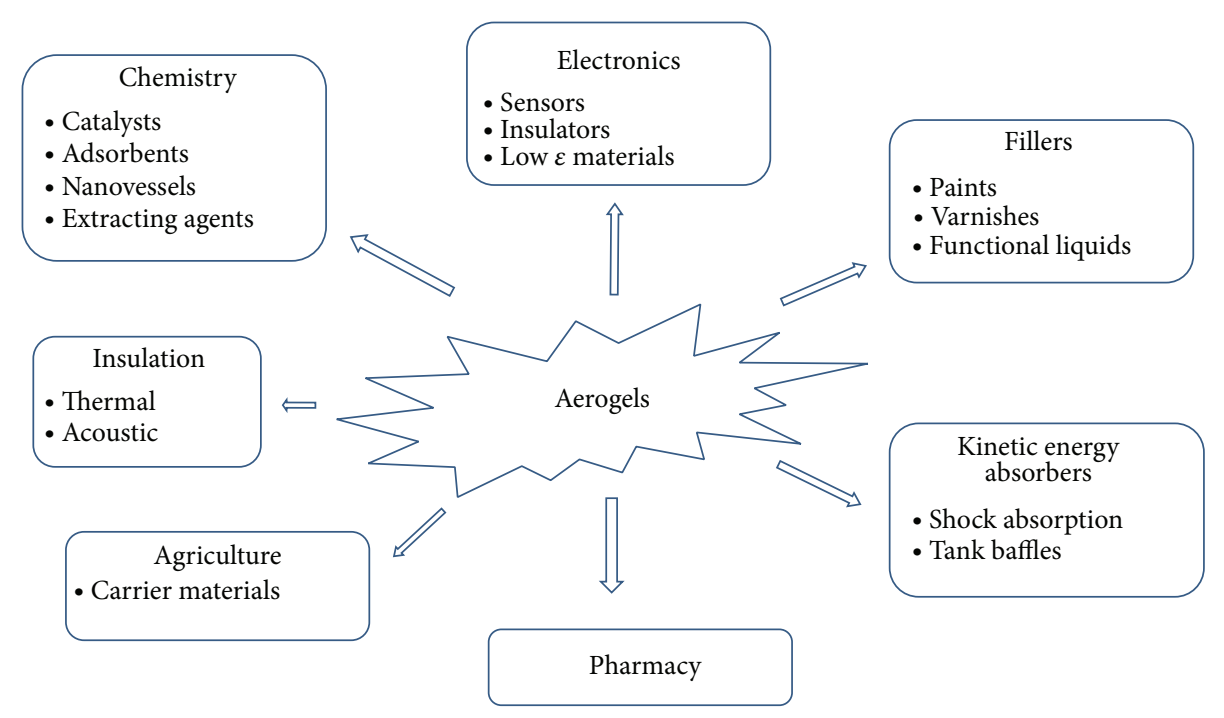

FIgURE 4: Different applications of aerogels.

powders, or thin films and make them promising materials for application in adsorption and catalysis [47, 48]. Organic polymer aerogels are important nanoporous materials and their nanopore structures can be modified by the chemical reactions. These properties enable carbon nanotube aerogels potential improvement over current carbon aerogels for applications such as sensors, actuators, electrodes, and thermoelectric devices [49]. The porosity provides both molecular accessibility and rapid mass transport via diffusion and for these reasons aerogels have been part of the heterogeneous catalytic materials field for over 50 years. The high porosity and mesoscopic pore diameters of aerogel structures enable the electrolyte to penetrate the entire aerogel particle [50].

An aerogel possesses the following characteristics [22].

(1) Property characteristics
(i) Ultralow thermal conductivity
(ii) Ultralow refractive index
(iii) Ultralow dielectric constant
(iv) High surface area
(v) High refractive index
(vi) Ultralow relative density
(vii) Ultrahigh porosity

(2) Structure characteristics

(i) Gel-like structure on nanoscale coherent skeletons andpores

(ii) Hierarchical and fractal microstructure

(iii) Macroscopic monolith

(iv) Randomly crosslinking network

(v) Noncrystalline matter.

\section{Advantages of Aerogels}

Aerogels are regarded as one of the most promising high performance thermal insulation materials for building applications today. With a low thermal conductivity $(\sim 13 \mathrm{~mW} / \mathrm{mK})$, they show remarkable characteristics compared to traditional thermal insulation materials. Also higher transmittances in the solar spectrum are of great interest for the construction sector. Another advantage of aerogels is their visible transparency for insulation applications which will allow their use in windows and skylights which give architects and engineers the opportunity of reinventing architectural solutions [51]. For example, the low thermal conductivity, a high solar energy, and daylight transmittance in monolithic silica aerogel make it a very interesting material for use in highly energy efficient windows [52]. For cryogenic systems, multilayered insulation (MLI) is the insulation of choice. However, MLI requires a high vacuum for optimal effectiveness. Powder insulations such as glass microspheres and aerogel beads have shown promise at soft vacuums and have a structural advantage in that they are far simpler to install and maintain $[53,54]$. Due to porous structure and low density, aerogels can trap space projectiles travelling with hypervelocity speed (order of $\mathrm{km} \mathrm{s}^{-1}$ ). NASA used aerogel to trap space dust particles and for thermal insulation of space suits [55-57]. One of the promising applications that promote the development of high quality transparent silica aerogel was the use of this low density material in physics as Cherenkov detector [58].

Our indoor environments are polluted by releasing many pollutants like chloride from tap-water, VOCs from organic solvents, formalin from furniture and paints, $\mathrm{SO}_{x}$ and $\mathrm{NO}_{x}$ from incomplete combustion of gasses and many hydrocarbons, and so on. Airborne contaminants are responsible for increasing some respiratory problems and allergies like asthma. The conversion of airborne contaminants into nontoxic compounds is an effective pathway for their removal and 
to protect our environment. Aerogels can also be used in air purification by removal of airborne contaminants and protect our environment by pollutants [59]. Aerogels are potentially more environmentally friendly than noble metal catalysts due to the negative environmental impact associated with mining and processing the metals [60].

Modification of aerogels is essential to achieve specific functionality and this tailoring can start during the sol-gel process either after gelation or after obtaining the aerogel. This can be done via (a) surface functionalization of aerogels for regulating the adsorption capacity and (b) applying a polymeric coating on aerogel surface. Hybrid aerogels can encompass the intrinsic properties of aerogels (high porosity and surface area) with the mechanical properties of inorganic components and the functionality and biodegradability of biopolymers [61-63].

\section{Limitations of Aerogels}

Widespread uses of aerogel materials are restricted at present mainly due to their

(i) High production costs,

(ii) Poor mechanical properties,

(iii) Health issues.

Supercritical drying is the most expensive and risky aspect of aerogel making process [64]. A highly desirable goal in aerogel preparation is the elimination of the supercritical drying process. For example, Guo and Guadalupe have succeeded in synthesizing a silica based aerogel from a metastable lamellar composite through cooperative interaction between silica and surfactant species [65]. The surfactant molecules used to generate pores can be removed from the silica network through conventional solvent extraction. The porous structure is stable during this procedure, in which no supercritical extraction is used [66]. Silica aerogels are very fragile but strength of silica aerogel monoliths has been improved by a factor of $>100$ through crosslinking the nanoparticle building blocks of preformed silica hydrogels with poly(hexamethylene diisocyanate). These composite monoliths are much less hygroscopic than native silica, and they do not collapse when in contact with liquids [67].

Aerogels are a mechanical irritant to the eyes, skin, respiratory tract, and digestive system. Small aerogel particles can potentially cause silicosis, and so forth, when inhaled and can induce dryness of the skin, eyes, and mucous membranes. Therefore, protective gear including respiratory protection, gloves, and eye goggles must be worn while handling aerogels [68].

\section{Conclusions}

Paints and coatings can be used for thermal insulation of buildings and work has been done also in CSIR-CBRI [69]. But aerogels are fast becoming alternate material of choice for thermal insulation due to their ultralow thermal conductivity. In the preparation of aerogels supercritical drying is the most effective process. In the conventional preparation of aerogels,

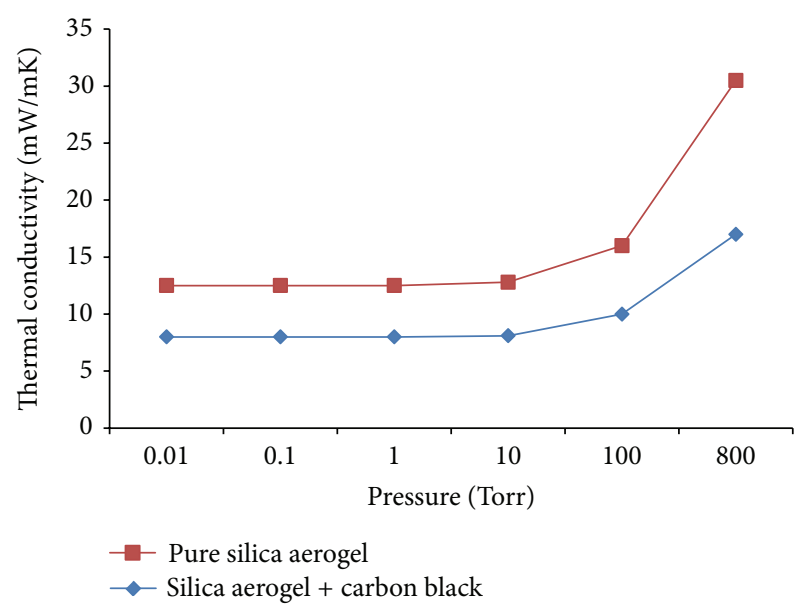

FIGURE 5: Thermal conductivity versus pressure curves for (i) pure silica aerogel and (ii) single-step silica aerogel with $9 \%$ (wt/wt) carbon black [70].

expensive raw materials and supercritical drying are used which prohibit commercialization. It is clear that for the large scale commercial aerogel production cost and risk have to be reduced. Aerogels can only be used as building material if we can utilize their highly thermal insulation properties with light weight and low cost.

There is little that can be done to reduce thermal transport through the solid structure of aerogels. Lower density aerogels can be prepared (as low as $0.003 \mathrm{~g} / \mathrm{cm}^{3}$ ), which reduces the amount of solid present, but this leads to aerogels that are mechanically weaker. Additionally, as the amount of solids decreases the mean pore diameter increases (with an increase in the gaseous component of the conductivity). These are, therefore, generally not suitable for insulation applications. Carbon is an effective absorber of infrared radiation and, in some cases, actually increases the mechanical strength of the aerogel. At ambient pressure the addition of carbon lowers the thermal conductivity from 0.017 to $0.0135 \mathrm{~W} / \mathrm{mK}$ [Figure 5]. The minimum value for the carbon composite of $\sim 0.0042$ $\mathrm{W} / \mathrm{mK}$ corresponds to $\sim \mathrm{R} 30 /$ inch. Hence, conclusion can be drawn that aerogels have great future potential in a wide range of applications as energy efficient insulation, windows, acoustics, and so forth [41, 70,71].

Chiral mesoporous $\mathrm{SiO}_{2}$ (CMS) as shown in Figure 6 can be synthesized with amino acid block copolymers and their acoustically induced optical Kerr effects (AIOKE) were found very high compared to nonchiral $\mathrm{SiO}_{2}$ and therefore CMS can be used in acoustically operated quantum electronic devices [72]. Recently cellulose nanofibril (CNF) aerogels with superior wet resilence and water activated shape recovery were fabricated without chemical crosslinking by ice crystal templated self assembly of TEMPO oxidised CNFs via cyclic freezing thawing method.Main challenge lies in the strengthening of aerogels either by crosslinking with cellulosic polymers or the incorporation of cellulose-based nanofibres. Other challenge is lowering the production cost of composite/hybrid aerogel materials via ambient drying and continuous production technology. 


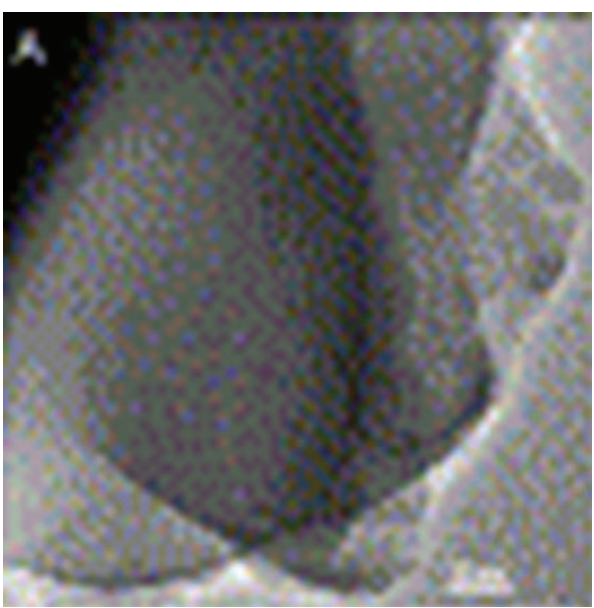

(a)

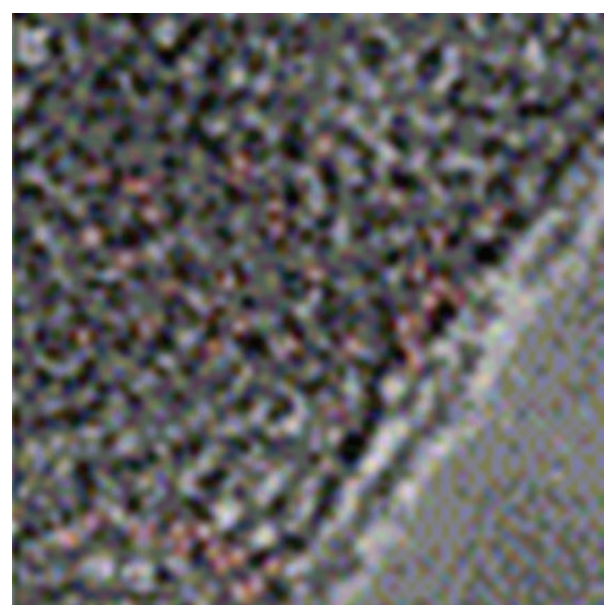

(b)

Figure 6: HRTEM images of chiral Ex-SiO $2-\mathrm{CBC}$, (a) at low and (b) at high resolution [72].

\section{Conflict of Interests}

The authors declare that there is no conflict of interests regarding the publication of this paper.

\section{Acknowledgment}

The authors are grateful to the Director, CSIR-CBRI, for his continuous guidance and encouragement.

\section{References}

[1] A. D. McNaught and A. Wilkinson, Compendium of Chemical Terminology, IUPAC Goldbook, PAC, 2007, 791801, Blackwell Science, Oxford, Cambridge, UK, 2nd edition.

[2] M. A. Aegerter, N. Leventis, and M. M. Koebel, Aerogels Handbook, Springer, New York, NY, USA, 2011.

[3] "Guinness Records Names JPL's Aerogel World's Lightest Solid," NASA Jet Propulsion Laboratory, 2002.

[4] K. Higa, "Aerogel-the insulative frozen smoke," Illumin, vol. 14, no. 3, p. 1, 2014.

[5] S. S. Kistler, "Coherent expanded aerogels and jellies," Nature, vol. 127, no. 3211, p. 741, 1931.

[6] D. M. Smith, R. Deshpande, and C. J. Brinker, "Preparation of low-density aerogels at ambient pressure for thermal insulation," Ceramic Transactions, vol. 31, pp. 71-80, 1993.

[7] S. T. Mayer, R. W. Pekala, and J. L. Kaschmitter, "Aerocapacitor. An electrochemical double-layer energy-storage device," Journal of the Electrochemical Society, vol. 140, no. 2, pp. 446-451, 1993.

[8] N. Leventis, N. Chandrasekaran, C. Sotiriou-Leventis, and A. Mumtaz, "Smelting in the age of nano: iron aerogels," Journal of Materials Chemistry, vol. 19, no. 1, pp. 63-65, 2009.

[9] B. C. Tappan, M. H. Huynh, M. A. Hiskey et al., "Ultralowdensity nanostructured metal foams: combustion synthesis, morphology, and composition," Journal of the American Chemical Society, vol. 128, no. 20, pp. 6589-6594, 2006.

[10] N. Hüsing and U. Schubert, "Aerogels-airy materials: chemistry, structure, and properties," Angewandte Chemie International Edition, vol. 37, no. 1-2, pp. 22-45, 1998.
[11] K. Richter, P. M. Norris, and C. L. Chang, "Aerogels: applications, structure and heat transfer phenomena," in Review on Heat Transfer, V. Prasad, Y. Jaluria, and G. Chen, Eds., vol. 6, chapter 2, pp. 61-114, 1995.

[12] L. W. Hrubesh, "Aerogel applications," Journal of Non-Crystalline Solids, vol. 225, no. 1-3, pp. 335-342, 1998.

[13] M. Schmidt and F. Schwertfeger, "Applications for silica aerogel products," Journal of Non-Crystalline Solids, vol. 225, no. 1-3, pp. 364-368, 1998.

[14] J. Fricke, “Thermal transport in porous superinsulations," in Aerogels, J. Fricke, Ed., vol. 6 of Springer Proceedings in Physics, pp. 94-103, 1986.

[15] Z. Novak and Ž. Knez, "Diffusion of methanol-liquid $\mathrm{CO}_{2}$ and methanol-supercritical $\mathrm{CO}_{2}$ in silica aerogels," Journal of NonCrystalline Solids, vol. 221, no. 2-3, pp. 163-169, 1997.

[16] H. Tamon, T. Kitamura, and M. Okazaki, "Preparation of silica aerogel from TEOS," Journal of Colloid and Interface Science, vol. 197, no. 2, pp. 353-359, 1998.

[17] D. M. Smith, A. Maskara, and U. Boes, "Aerogel-based thermal insulation," Journal of Non-Crystalline Solids, vol. 225, no. 1-3, pp. 254-259, 1998.

[18] A. Soleimani Dorcheh and M. H. Abbasi, "Silica aerogel; synthesis, properties and characterization," Journal of Materials Processing Technology, vol. 199, no. 1, pp. 10-26, 2008.

[19] Y. C. Chiang, W. Y. Cheng, and S. Y. Lu, “Titania aerogels as a superior mesoporous structure for photoanodes of dyesensitized solar cells," International Journal of Electrochemical Science, vol. 7, no. 8, pp. 6910-6919, 2012.

[20] P. Arora, S. Sharma, S. K. Ghoshal, N. Dilbaghi, and A. Chaudhury, "A functional approach toward xerogel immobilization for encapsulation biocompatibility of Rhizobium toward biosensor," Frontiers in Biology, vol. 8, no. 6, pp. 626-631, 2013.

[21] L. Forest, V. Gibiat, and T. Woignier, "Biot's theory of acoustic propagation in porous media applied to aerogels and alcogels," Journal of Non-Crystalline Solids, vol. 225, no. 1-3, pp. 287-292, 1998.

[22] A. Du, B. Zhou, Z. Zhang, and J. Shen, "A special material or a new state of matter: a review and reconsideration of the aerogel," Materials, vol. 6, no. 3, pp. 941-968, 2013. 
[23] C. J. Brinker, R. Sehgal, S. L. Hietala et al., "Sol-gel strategies for controlled porosity inorganic materials," Journal of Membrane Science, vol. 94, pp. 85-102, 1994.

[24] J. L. Gurav, D. Y. Nadargi, and A. V. Rao, "Effect of mixed Catalysts system on TEOS-based silica aerogels dried at ambient pressure," Applied Surface Science, vol. 255, no. 5, pp. 3019-3027, 2008.

[25] A. Acharya, D. Joshi, and V. A. Gokhale, "AEROGEL-a promising building material for sustainable buildings," Chemical and Process Engineering Research, vol. 9, pp. 1-6, 2013.

[26] I. Smirnova, S. Suttiruengwong, and W. Arlt, "Feasibility study of hydrophilic and hydrophobic silica aerogels as drug delivery systems," Journal of Non-Crystalline Solids, vol. 350, pp. 54-60, 2004.

[27] R. P. Patel, N. S. Purohit, and A. M. Suthar, "An overview of silica aerogels," International Journal of ChemTech Research, vol. 1, no. 4, pp. 1052-1057, 2009.

[28] A. C. Pierre and G. M. Pajonk, "Chemistry of aerogels and their applications," Chemical Reviews, vol. 102, no. 11, pp. 4243-4265, 2002.

[29] Y. K. Akimov, "Fields of application of aerogels (review)," Instruments and Experimental Techniques, vol. 46, no. 3, pp. 287-299, 2003.

[30] G. M. Pajonk, "Some applications of silica aerogels," Colloid and Polymer Science, vol. 281, no. 7, pp. 637-651, 2003.

[31] A. Bisson, A. Rigacci, D. Lecomte, E. Rodier, and P. Achard, "Drying of silica gels to obtain aerogels: phenomenology and basic principles," Drying Technology, vol. 21, no. 4, pp. 593-628, 2003.

[32] C. J. Lee, G. S. Kim, and S. H. Hyun, "Synthesis of silica aerogels from waterglass via new modified ambient drying," Journal of Materials Science, vol. 37, no. 11, pp. 2237-2241, 2002.

[33] A. C. Pierre, "The chemistry of precursors solutions," in Introduction to Sol-Gel Processing, vol. 1, chapter 2, pp. 11-89, 1998.

[34] A. P. Ambekar and P. Bagade, "A review on: aerogel—world's lightest solid," Popular Plastics \& Packaging, vol. 51, pp. 96-102, 2006.

[35] A. C. Pierre and A. Rigacci, " $\mathrm{SiO}_{2}$ aerogels," in Aerogels Handbook, M. A. Aegerter, N. Leventis, and M. M. Koebel, Eds., Advances in Sol-Gel Derived Materials and Technologies, pp. 21-45, 2011.

[36] C. E. Carraher Jr., "General topics: silica aerogels-properties and uses," Polymer News, vol. 30, no. 12, pp. 386-388, 2005.

[37] C. E. Carraher Jr., "Silica aerogels-synthesis and history," Polymer News, vol. 30, pp. 62-64, 2005.

[38] G. M. Pajonk, “Transparent silica aerogels," Journal of NonCrystalline Solids, vol. 225, no. 1-3, pp. 307-314, 1998.

[39] A. Venkateswara Rao and G. M. Pajonk, "Effect of methyltrimethoxysilane as a co-precursor on the optical properties of silica aerogels," Journal of Non-Crystalline Solids, vol. 285, no. 1-3, pp. 202-209, 2001.

[40] A. V. Rao and R. R. Kalesh, "Comparative studies of the physical and hydrophobic properties of TEOS based silica aerogels using different co-precursors," Science and Technology of Advanced Materials, vol. 4, no. 6, pp. 509-515, 2003.

[41] X. Lu, R. Caps, J. Fricke, C. T. Alviso, and R. W. Pekala, "Correlation between structure and thermal conductivity of organic aerogels," Journal of Non-Crystalline Solids, vol. 188, no. 3, pp. 226-234, 1995.

[42] S.-K. Kang and S.-Y. Choi, "Synthesis of low-density silica gel at ambient pressure: effect of heat treatment," Journal of Materials Science, vol. 35, no. 19, pp. 4971-4976, 2000.
[43] R. W. Pekala and F. M. Kong, "Resorcinol-formaldehyde aerogels and their carbonized derivatives," Polymer Preprints, vol. 30, no. 1, pp. 221-223, 1989.

[44] P. J. M. Carrott, L. M. Marques, and M. M. L. R. Carrott, "Core-shell polymer aerogels prepared by co-polymerisation of 2,4-dihydroxybenzoic acid, resorcinol and formaldehyde," Microporous and Mesoporous Materials, vol. 158, pp. 170-174, 2012.

[45] F. Shi, L. Wang, J. Liu, and M. Zeng, "Effect of heat treatment on silica aerogels prepared via ambient drying," Journal of Materials Science and Technology, vol. 23, no. 3, pp. 402-406, 2007.

[46] B. Hosticka, P. M. Norris, J. S. Brenizer, and C. E. Daitch, "Gas flow through aerogels," Journal of Non-Crystalline Solids, vol. 225, no. 1-3, pp. 293-297, 1998.

[47] C. Moreno-Castilla and F. J. Maldonado-Hódar, "Carbon aerogels for catalysis applications: an overview," Carbon, vol. 43, no. 3, pp. 455-465, 2005.

[48] M. B. Bryning, D. E. Milkie, M. F. Islam, L. A. Hough, J. M. Kikkawa, and A. G. Yodh, "Carbon nanotube aerogels," Advanced Materials, vol. 19, no. 5, pp. 661-664, 2007.

[49] Y. Tao, M. Endo, and K. Kaneko, "A review of synthesis and nanopore structures of organic polymer aerogels and carbon aerogels," Recent Patents on Chemical Engineering, vol. 1, pp. 192-200, 2008.

[50] W. Dong, J. S. Sakamoto, and B. Dunn, "Electrochemical properties of vanadium oxide aerogels," Science and Technology of Advanced Materials, vol. 4, no. 1, pp. 3-11, 2003.

[51] R. Baetens, B. P. Jelle, and A. Gustavsen, "Aerogel insulation for building applications: a state-of-the-art review," Energy and Buildings, vol. 43, no. 4, pp. 761-769, 2011.

[52] K. I. Jensen, "Passive solar component based on evacuated monolithic silica aerogel," Journal of Non-Crystalline Solids, vol. 145, pp. 237-239, 1992.

[53] J. E. Fesmire, S. D. Augustynowicz, and S. Rouanet, "Aerogel beads as cryogenic thermal insulation system," in Proceedings of the Cryogenic Engineering Conference (CEC '01), vol. 613 of Advances in Cryogenic Engineering, pp. 1541-1548, July 2001.

[54] A. L. Nayak and C. L. Tien, "Thermal conductivity of microsphere cryogenic insulation," Advances in Cryogenic Engineering, vol. 22, pp. 251-262, 1977.

[55] R. Wawryk and J. Rafalowicz, "The influence of residual gas pressure on the thermal conductivity of microsphere insulations," International Journal of Thermophysics, vol. 9, no. 4, pp. 611-625, 1988.

[56] M. J. Burchell, M. J. Cole, M. C. Price, and A. T. Kearsley, "Experimental investigation of impacts by solar cell secondary ejecta on silica aerogel and aluminum foil: implications for the Stardust Interstellar Dust Collector," Meteoritics and Planetary Science, vol. 47, no. 4, pp. 671-683, 2012.

[57] J. E. Fesmire, "Aerogel insulation systems for space launch applications," Cryogenics, vol. 46, no. 2-3, pp. 111-117, 2006.

[58] M. Tabata, I. Adachi, Y. Ishii, H. Kawai, T. Sumiyoshi, and H. Yokogawa, "Development of transparent silica aerogel over a wide range of densities," Nuclear Instruments and Methods in Physics Research A: Accelerators, Spectrometers, Detectors and Associated Equipment, vol. 623, no. 1, pp. 339-341, 2010.

[59] N. J. H. Dunna, M. K. Carrolla, and A. M. Anderson, "Characterization of alumina and nickel-alumina aerogels prepared via rapid supercritical extraction," Polymer Preprints, vol. 52, no. 1, pp. 250-251, 2011. 
[60] R. Yang, Y.-P. Zhang, and R.-Y. Zhao, "An improved model for analyzing the performance of photocatalytic oxidation reactors in removing volatile organic compounds and its application," Journal of the Air and Waste Management Association, vol. 54, no. 12, pp. 1516-1524, 2004.

[61] K. Kanamori, "Organic-inorganic hybrid aerogels with high mechanical properties via organotrialkoxysilane-derived solgel process," Journal of the Ceramic Society of Japan, vol. 119, no. 1385, pp. 16-22, 2011.

[62] J. L. Plawsky, H. Littman, and J. D. Paccione, "Design, simulation, and performance of a draft tube spout fluid bed coating system for aerogel particles," Powder Technology, vol. 199, no. 2, pp. 131-138, 2010.

[63] H. Ramadan, T. Coradin, S. Masse, and H. El-Rassy, "Synthesis and characterization of mesoporous hybrid silicapolyacrylamide aerogels and xerogels," Silicon, vol. 3, no. 2, pp. 63-75, 2011

[64] J. Fricke and A. Emmerling, "Aerogels-recent progress in production techniques and novel applications," Journal of SolGel Science and Technology, vol. 13, no. 1-3, pp. 299-303, 1999.

[65] Y. Guo and A. R. Guadalupe, "Functional silica aerogel from metastable lamellar composite," Chemical Communications, no. 4, pp. 315-316, 1999.

[66] S. Dai, Y. H. Ju, H. J. Gao, J. S. Lin, S. J. Pennycook, and C. E. Barnes, "Preparation of silica aerogel using ionic liquids as solvents," Chemical Communications, no. 3, pp. 243-244, 2000.

[67] N. Leventis, C. Sotiriou-Leventis, G. Zhang, and A.-M. M. Rawashdeh, "Nanoengineering strong silica aerogels," Nano Letters, vol. 2, no. 9, pp. 957-960, 2002.

[68] Cryogel 5201, 10201 Safety Data Sheet, Aspen Aerogels. 11/13/07.

[69] P. C. Thapliyal and S. R. Karade, "Studies on physico-mechanical behavior of thermal insulating coatings for buildings," in Proceedings of the International Conference on Advanced Materials for Energy Efficient Buildings (AME2B '13), no. TS4, p. 52, 2013.

[70] T. Rettlebach, J. Sauberlich, S. Korder, and J. Fricke, “Thermal conductivity of silica aerogel powders at temperatures from 10 to 275K," Journal of Non-Crystalline Solids, vol. 186, pp. 278-284, 1995.

[71] J. V. Accorsi, "The impact of carbon black morphology and dispersion on the weatherability of polyethylene," KGK-Kautschuk und Gummi Kunststoffe, vol. 54, no. 6, pp. 321-326, 2001.

[72] P. Paik, Y. Mastai, I. Kityk, P. Rakus, and A. Gedanken, "Synthesis of amino acid block-copolymer imprinted chiral mesoporous silica and its acoustically-induced optical Kerr effects," Journal of Solid State Chemistry, vol. 192, pp. 127-131, 2012.

[73] http://www.cabot-corp.com/.

[74] M. A. B. Meador, B. N. Nguyen, H. Guo et al., "Aerogels: thinner, lighter, stronger," 2011, http://www.nasa.gov/topics/technology/ features/aerogels.html.

[75] Aspen Aerogels, "Insulated building materials," US Patent 7771609, 2010.

[76] Aspen Aerogels, "Insulated building materials," US Patent 8277676, 2012.

[77] http://www.aerogel.com/.

[78] 2011, http://www.chem-eng.kyushu-u.ac.jp/e/research.html.

[79] A.-Y. Jeong, S.-M. Koo, and D.-P. Kim, "Characterization of hydrophobic $\mathrm{SiO}_{2}$ powders prepared by surface modification on wet gel," Journal of Sol-Gel Science and Technology, vol. 19, no. 13, pp. 483-487, 2000.
[80] T. Błaszczyński, A. Ślosarczyk, and M. Morawski, "Synthesis of aerogel by supercritical drying method," Procedia Engineering, vol. 57, pp. 200-206, 2013. 

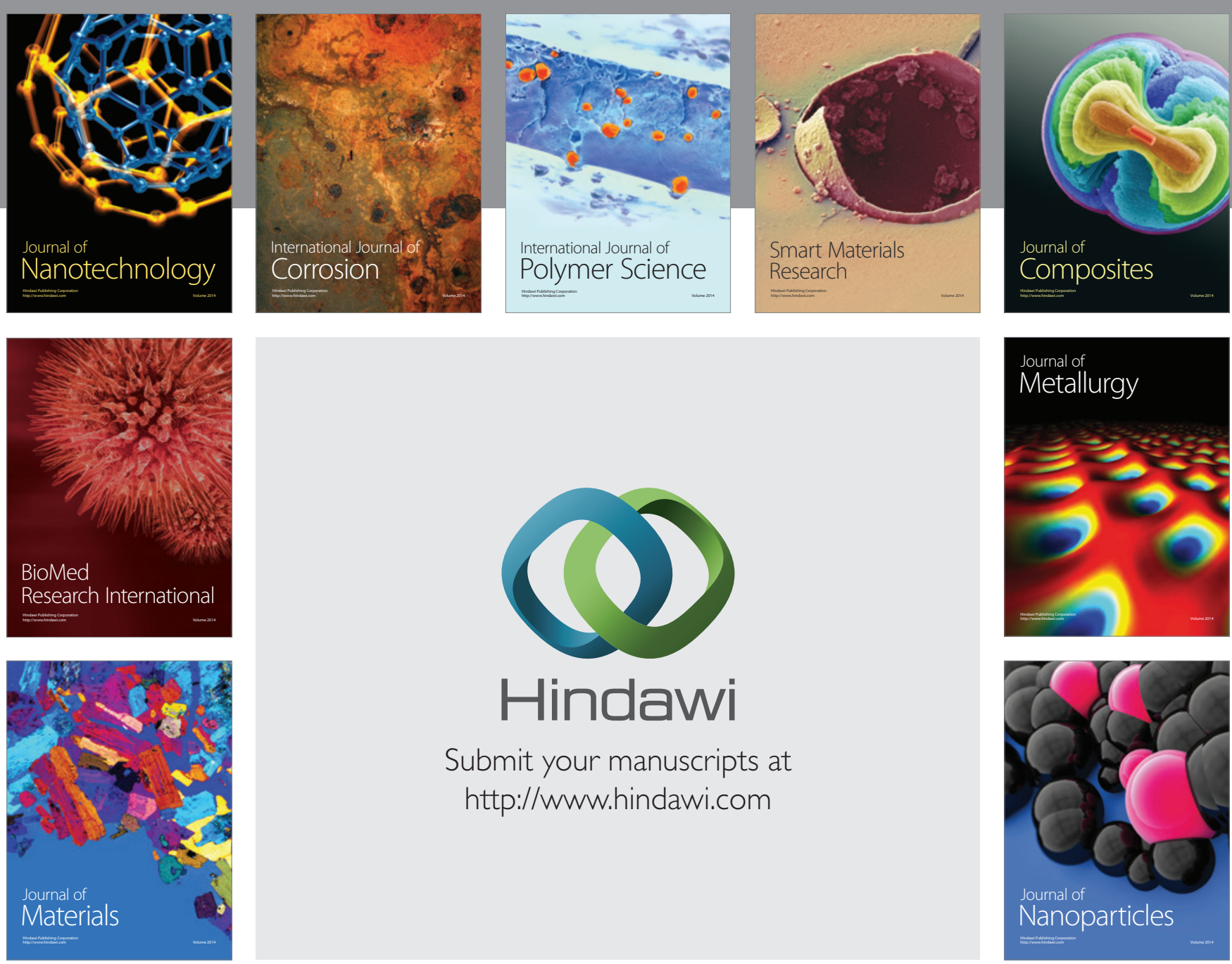

Submit your manuscripts at http://www.hindawi.com
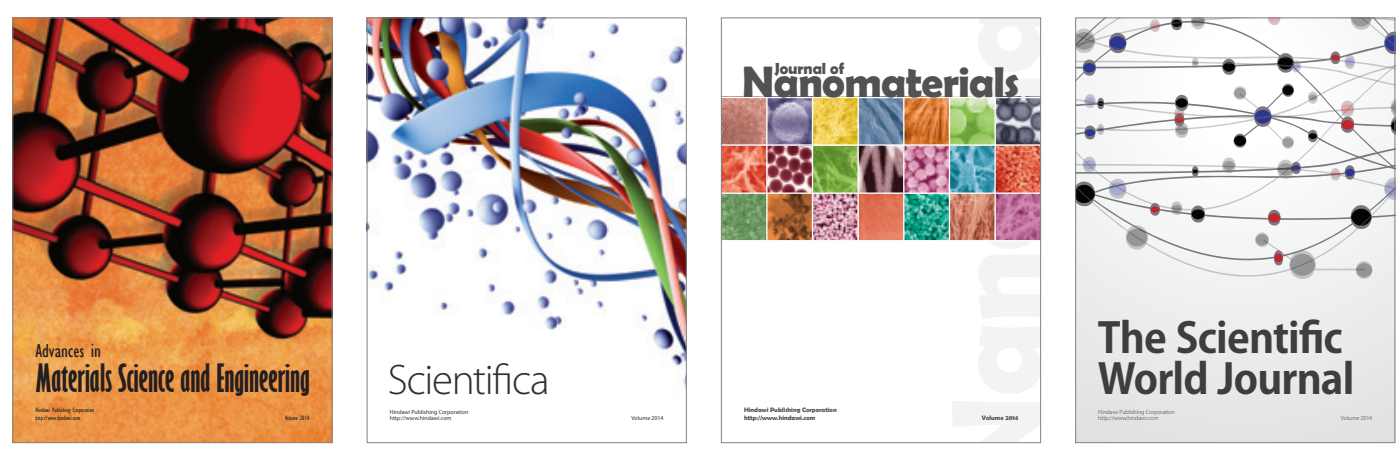

\section{The Scientific World Journal}
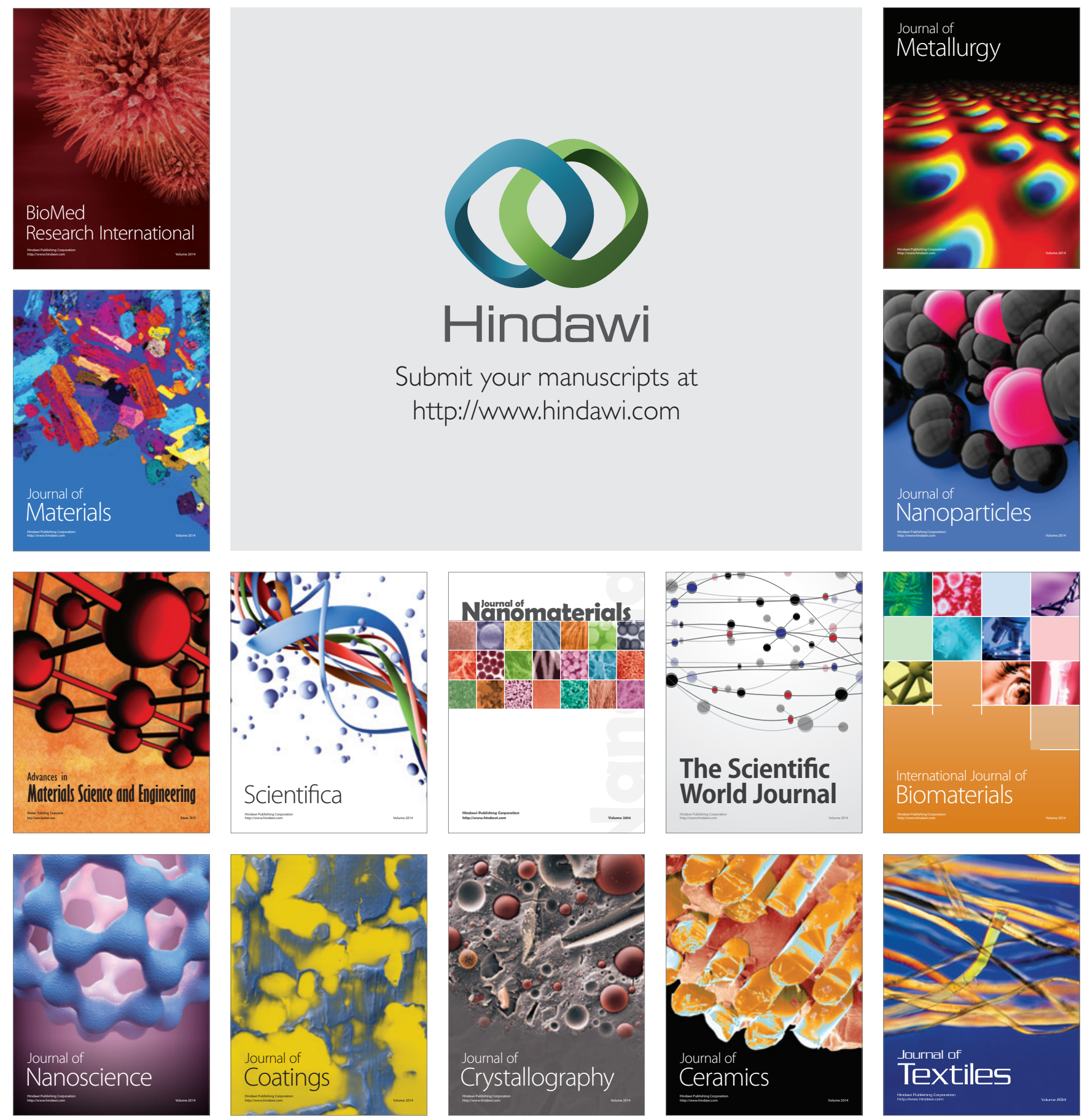